\title{
AIDA Model Application for TV Commercials in Nepal
}

\author{
Bhoj Raj Aryal
}

COMMERCIAL TELEVISION HAS more than fifty years of history, and is present almost every corner of the glove. In the last few years, with the introduction of satellite broadcasting and the development of digital signals (which allows several channels to use the same bandwidth) the structure and character of TV have been changing rapidly. TV's share of total media spending by advertisers has been increasing globally. British consumers are among the world's heaviest TV viewers, watching on an average 3.5 hours a day (White 2000). Indisputably advertising is a discipline that is booming rapidly all over the world. This growth is easily understandable by the fact that, advertisement has outrun all other promotional means in taking the product near to the customer with the speed and mode desired. The irony of advertisement is such that one cannot sell the product anymore (might be best in quality and competitive in price) without the means of canvassing, "the advertisement": advertisement connects the product with the consumer

The history of electronic media in Nepal goes as far as fifty years back, the only audio media in the country was established in 1951. Nepal Television started its first audio visual media transmission in Katmandu Valley in 1984. Even today large part of the remote rural areas of the kingdom does not receive clear transmission. Currently several private cable channels such as Channel Nepal, Kantipur Television, Image Channel, Metro Channels, etc. are in operation. In addition numerous foreign channels reach to the households in urban and sub-urban areas of Nepal.

\section{Objectives}

The main objective of this paper is to analyze the TV Commercials (TVC) its recall situation in both urban and sub-urban areas, and its verification with AIDA model, which was developed by Elmo St. J. Lewis. The first model of this kind was formulated by Elmo St. J. Lewis in 1898 and was called AIDA which stands for attention-interest-desire-action. This type of model of how ads work is called a 'hierarchy of effects' model. On the whole, this paper is concentrated to AIDA model application for TVC in Nepal.

\section{Population and Sampling}

The paper is based on research conducted during the $\mathrm{PhD}$ course preparation. The particular work is the outcome of primary data. Kathmanu Municipal Corporation, ward 10, Baneshwor (Urban) and Thali Danchhi Village Development Committee (VDC), Danchhi (sub-urban) areas were taken as a study area for comparative audience survey. The collected data were set into tabular as well as bar diagram. Altogether 308 audiences were taken for primary data, 154 persons from each location. The population and sample profile of the study are given in Table 1.

Table 1: Population and Sample Profile of the Study

\begin{tabular}{|l|c|c|c|c|c|c|}
\hline Population & Population & Sample & $\begin{array}{l}\text { Percentag } \\
\text { e }\end{array}$ & $\begin{array}{l}\text { Q.distribute } \\
\text { d }\end{array}$ & $\begin{array}{l}\text { R. } \\
\text { Received }\end{array}$ & $\begin{array}{l}\text { Received } \\
\%\end{array}$ \\
\hline Audience Kath-10 & 13860 & 200 & 10 & 200 & 154 & 77 \\
\hline $\begin{array}{l}\text { Thali Danchhi } \\
\text { VDC 1,2,5,8 }\end{array}$ & 13860 & 220 & 10 & 220 & 154 & 70 \\
\hline Total & 27720 & 420 & 10 & 420 & 308 & 73.5 \\
\hline
\end{tabular}

Source: Field survey, 2003. 


\section{The Journal of Nepalese Business Studies}

In urban area, 200 questionnaires were distributed and 154 were returned (77\%) from audiences. Similarly, in sub-urban area, 220 questionnaires were distributed and 154 were (70\%) returned.

\section{Analysis}

\subsection{Media of Viewers Priority}

Sixty-four percent of the urban audience watches domestic channels whereas $36 \%$ of them view foreign channels. But in case of sub-urban, $71 \%$ watch domestic channels and $29 \%$ foreign channels. On an average, $67 \%$ audience watch domestic channels like, Nepal TV, Channel Nepal, Kantipur TV, Image Channel whilst, 33\% still prefer to watch foreign channels.

\subsection{Motivating Factors in TVC}

Fig.1: Channel Viewership in Nepal

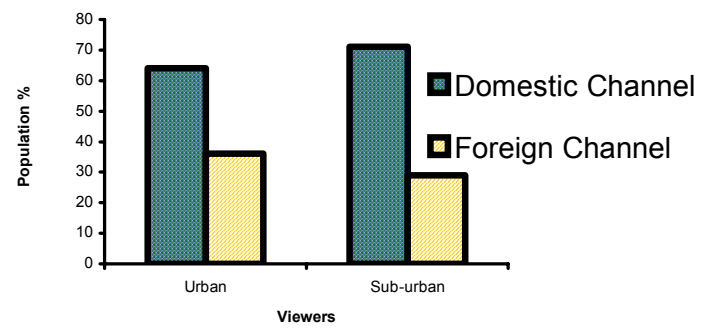

There is no doubt that the ad should be SMART (simple, meaningful, articulate, relevant and to the point). Every advertiser tries to meet these attributes to the extent possible. So far as to fulfill these attributes they should meet other headlines like slogans, illustrations, blank space, price and others. Without these sub-headlines' best combinations, the total ad process would become a body without heart.

Table 2: Factors Motivating Consumers to Buy Products

\begin{tabular}{|l|c|c|c|c|c|c|}
\hline Factors & \multicolumn{2}{|l|}{ Urban } & \multicolumn{2}{l|}{ Sub-urban } & Total \\
\hline & $\mathrm{f}$ & $\%$ & $\mathrm{f}$ & $\%$ & $\mathrm{f}$ & $\%$ \\
\hline Slogans & 55 & 36 & 29 & 19 & 84 & 27 \\
\hline Illustrations & 57 & 37 & 69 & 45 & 126 & 41 \\
\hline Blank & & & & & & \\
Space & 2 & 1 & 12 & 8 & 14 & 5 \\
\hline Price & 23 & 15 & 19 & 45 & 42 & 14 \\
\hline Others & 17 & 11 & 25 & 16 & 42 & 14 \\
\hline Total & 154 & 100 & 154 & 100 & 308 & 100 \\
\hline
\end{tabular}

Source: Field survey, 2003

As depicted in Table 2, in urban areas $37 \%$ prefers illustration whereas $36 \%$ prefers slogans and price is a deciding factor for 15 percent. Similarly, while selecting the product in rural area, $45 \%$ claims to make decision based on price and $41 \%$ on illustration. Slogan is the deciding factor for 19 $\%$ of the selected audiences. The inference is that illustration is the first influencing factor at present in both urban and sub-urban settings. Accordingly the slogans and price are the $2^{\text {nd }}$ and $3^{\text {rd }}$ influencing factors as far as this research is concern. So advertisers should pay more attention on these factors.

\subsection{Recall on TV Commercials}

It is important that when a buyer goes to purchase a product, he/she should be able to recall the particular brand of interest. How long the consumer can recall the shape, color, the picture of the product would determine the period of such lease. In this case the ironic function of the consumers' mind plays the major role in his behavioral functions. This is possible when the advertiser, through persuasions and reminders, manage to gain control on the behavioral component of the consumer (Gillian Dyer 1999). 
Advertisers want to know how effective are their advertising messages and research services attempt to measure such effectiveness. Most measures of message effectiveness are related to recall or recognition-how well people can remember advertisement they have seen. This reliance on recall and recognition is based on the assumption that advertising will not have any effect (in sales) unless consumers can remember it.

While analyzing Fig. 2, we can observe that $86 \%$ of urban audience can recall some ads from TV and remaining $14 \%$ are unable to recall. Similarly, $66 \%$ sub-urban audience can recall from TV and that of $34 \%$ could not do so. The trend of urban audience

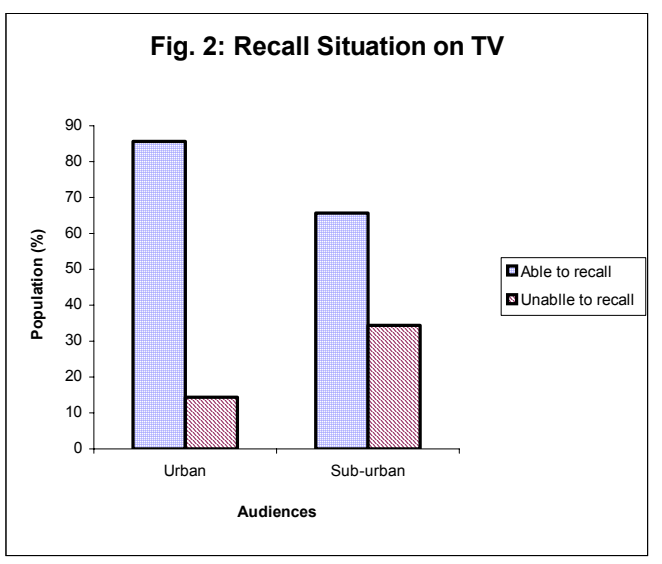
able to recall better than their rural counterpart can be attributed to the frequency of viewing television in these settings: urban dwellers watch TV more compare to their sub-urban fellows.

\subsection{Bases of Recall (TVC)}

Table 3 shows the basis of Ad recall. In ads there are several headlines and sub-headlines. Bases of recall are both headlines and sub-headlines on TVC. In urban area, almost $44 \%$ recall on the basis of outlook and $29.87 \%$ recall on the basis slogans and only $14.28 \%$ recall on the basis of illustration. Similarly, in sub-urban area, $40.90 \%$ recall on the basis of outlook and that of $27.27 \%$ and $16 \%$ recall on the basis illustrations and slogans.

Table 3: Bases on Advertisement Recall (TV)

\begin{tabular}{|l|c|c|c|c|c|c|}
\hline Medias & Urban & \multicolumn{2}{c|}{ Sub-Urban } & Total \\
\hline & $\mathrm{f}$ & $\%$ & $\mathrm{f}$ & $\%$ & $\mathrm{f}$ & $\%$ \\
\hline Slogans & 46 & 29.87 & 25 & 16.23 & 71 & 23.05 \\
\hline Illustrations & 22 & 14.28 & 42 & 27.27 & 64 & 20.77 \\
\hline View & 67 & 43.5 & 63 & 40.9 & 130 & 42.2 \\
\hline Price & 9 & 5.84 & 14 & 9.09 & 23 & 7.46 \\
\hline Others & 10 & 6.49 & 10 & 6.49 & 20 & 6.49 \\
\hline Total & 154 & 100 & 154 & 100 & 308 & 100 \\
\hline
\end{tabular}

Source: Field survey, 2003.

The conclusion is that outlook of the object, illustrations and slogans are major factors that can help to recall advertisement. So the advertisers should focus on these factors while preparing ads.

\subsection{Motivation on Advertised Products}

The product advertisements seems to have the significant influence one at least one third of the audience while about $50 \%$ of them claim to have only minor impact on their decision for opting to go for a product. Only $16 \%$ claim that they have no affect of ad what so ever on selecting the product they would be buying.

Martin Sorrell in 1997 explained that advertising through media is a loss of money and if it can be avoided this can save a lot of money for other purposes. However, in Nepalese media advertisement about $83 \%$ of the consumers have positive impact on the product advertisement. This positive change in psychology may increase the products selling and that may overcome the cost of advertisement thus clarifying Martin's concern. 
The prime task of advertisement is to change or reinforce an attitude in the consumers mind in favor of the product (Biswas 1999). That will depend on the quality of the advertisement which influence on recalling of the product ( shape and color of the product) (Schiffman and Kanuk 1996). In Nepalese product the quality of advertisement may not be able to give impressive slots to the consumer brain to reinforce the recall. That might explain the higher proportion of moderate impact (50\%) compare to the highly positive $33 \%$. Fig. 3 illustrates the detail.

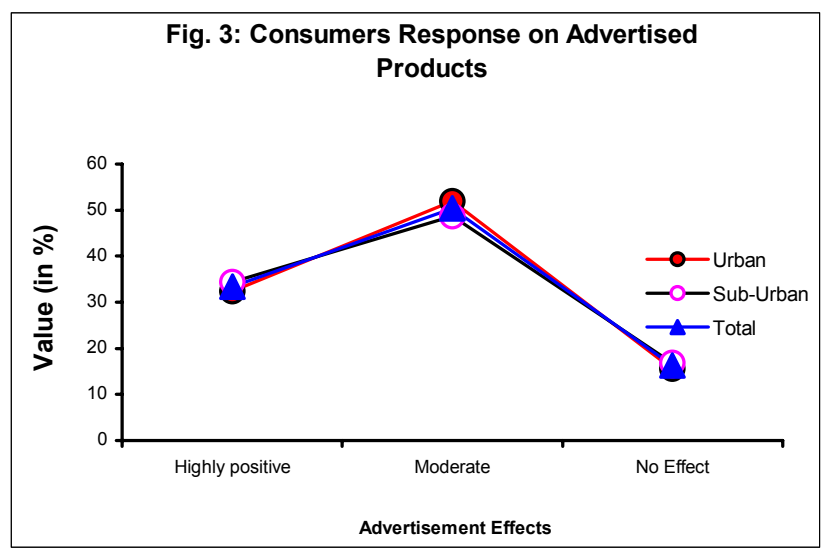

Table 4: Motivation on Advertised Products

\begin{tabular}{|l|c|c|c|c|c|c|}
\hline \multirow{3}{*}{ Ad Effects } & \multicolumn{6}{|c|}{ Respondents } \\
\cline { 2 - 7 } & \multicolumn{6}{|c|}{$\begin{array}{c}\text { Sub- } \\
\text { Urban }\end{array}$} \\
\cline { 2 - 7 } & Urban & $\mathrm{f}$ & $\%$ & $\%$ & $\mathrm{f}$ & $\%$ \\
\hline Highly & & & & & & \\
positive & 50 & 32 & 53 & 34 & 103 & 33 \\
\hline Moderate & 80 & 52 & 75 & 49 & 155 & 50 \\
\hline No Effect & 24 & 16 & 26 & 17 & 50 & 16 \\
\hline Total & 154 & 100 & 154 & 100 & 308 & 100 \\
\hline
\end{tabular}

Source: Field survey, 2003.

\subsection{Factors Motivating Consumers to Buy Products}

The factors responsible to motivate the consumers towards buying the products are Slogans, Illustrations, price, quality, availability, and premium. To see the effect of individual factors on the Nepalese consumers a research was conducted both in sub-urban and urban societies. Both the societies emphasized on quality of the goods, though the urban people were comparatively more sensitive to the quality of the product than sub-urban. Illustration and price of the commodity affect much more the sub-urban society than urban. These differences could be because of income as well as educational differences (demand theory of commodity).

Table 5: Factors Motivating Consumers to Buy Products

\begin{tabular}{|l|c|c|c|c|c|c|}
\hline \multirow{2}{*}{$\begin{array}{l}\text { Sub- } \\
\text { Headlines }\end{array}$} & \multicolumn{6}{|c|}{ Respondents } \\
\cline { 2 - 7 } & Urban & & \multicolumn{2}{c|}{ Sub-Urban } & \multicolumn{2}{c|}{ Total } \\
\cline { 2 - 7 } & $\mathrm{f}$ & $\%$ & $\mathrm{f}$ & $\%$ & $\mathrm{f}$ & $\%$ \\
\hline Slogans & 16 & 10 & 16 & 10 & 32 & 10 \\
\hline Illustrations & 11 & 7 & 19 & 12 & 30 & 10 \\
\hline Price & 6 & 4 & 25 & 16 & 31 & 10 \\
\hline Quality & 97 & 63 & 73 & 47 & 170 & 55 \\
\hline Availability & 13 & 8 & 8 & 5 & 21 & 7 \\
\hline Premium & 9 & 6 & 9 & 6 & 18 & 6 \\
\hline Others & 2 & 1 & 4 & 3 & 6 & 2 \\
\hline Total & 154 & 100 & 154 & 100 & 308 & 100 \\
\hline
\end{tabular}

Source: Field survey, 2003. 
AIDA Model Application for TV Commercials in Nepal

\subsection{Performance of Present TVC}

Fig. 4 shows the situation of present ad. In urban area about $78 \%$ audience said that present ad is not sufficient whereas the response figure for insufficiency of ad in sub-urban area is $59.74 \%$. Nevertheless, the majority of audiences in both areas suggest to improve the present ad scenario in the country.

\subsection{Bases of TVC Insufficient}

It has long been believed that advertisements work ultimately by their effects on people's attitudes.

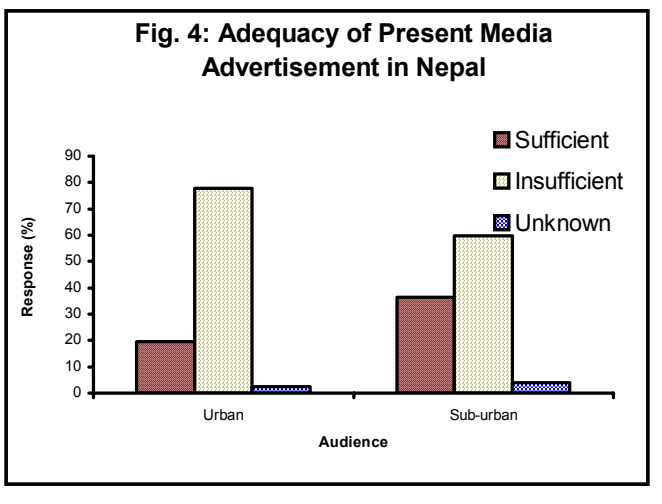
This is what persuasion is all about. So we ought to be able to measure changes in people's attitudes to our brand and its competitors, and use this information to forecast changes in the relative market shares. Similarly, if we can identify the key attitudes in our market, we can seek to strengthen our brand's position in respect to these.

Table 6: Basis of Advertisement Insufficient

\begin{tabular}{|l|c|c|c|c|c|c|}
\hline Bases & \multicolumn{2}{|c|}{ Urban } & \multicolumn{2}{c|}{ Sub-Urban } & \multicolumn{2}{|c|}{ Total } \\
\hline & $\mathrm{f}$ & $\%$ & $\mathrm{f}$ & $\%$ & $\mathrm{f}$ & $\%$ \\
\hline Language & 15 & 10 & 19 & 12 & 34 & 11 \\
\hline Culture & 4 & 3 & 8 & 5 & 12 & 4 \\
\hline Not Timely Ad & 13 & 8 & 12 & 8 & 25 & 8 \\
\hline More Provocative & 25 & 16 & 23 & 15 & 48 & 16 \\
\hline Lacking on Appropriate Info. & 61 & 40 & 32 & 21 & 83 & 27 \\
\hline No Response & 36 & 23 & 60 & 39 & 96 & 31 \\
\hline Total & 154 & 100 & 154 & 100 & 308 & 100 \\
\hline
\end{tabular}

Source: Field survey, 2003.

Forty percent urban audiences are with the opinion that present ad is unable to provide appropriate information; $16 \%$ are with the opinion that the present ad is more provocative and $10 \%$ reasoned it lacks to communicate due to language barriers (not available in mother tongue). Similarly $21 \%$ rural audience responded by saying it is lacking on giving appropriate information and $15 \%$ said it is unnecessarily provocative and $12 \%$ expressed that it is inappropriate because of language (not available in mother tongue). This clearly indicates that the present ad scenario is unable to meet peoples expectation to an extent desired.

\section{9 $\quad$ AIDA Model}

The first model of this kind of ad was formulated by Elmo St. J. Lewis in 1898 and was called AIDA. This type of model is called a 'hierarchy of effects' model. As mentioned (desired) by Lewis, the hierarchy of AIDA model has been verified both in sub-urban and urban society of Nepal as well. The awareness, interest, desire and action are in descending order and form an inverted pyramid. Relative proportion

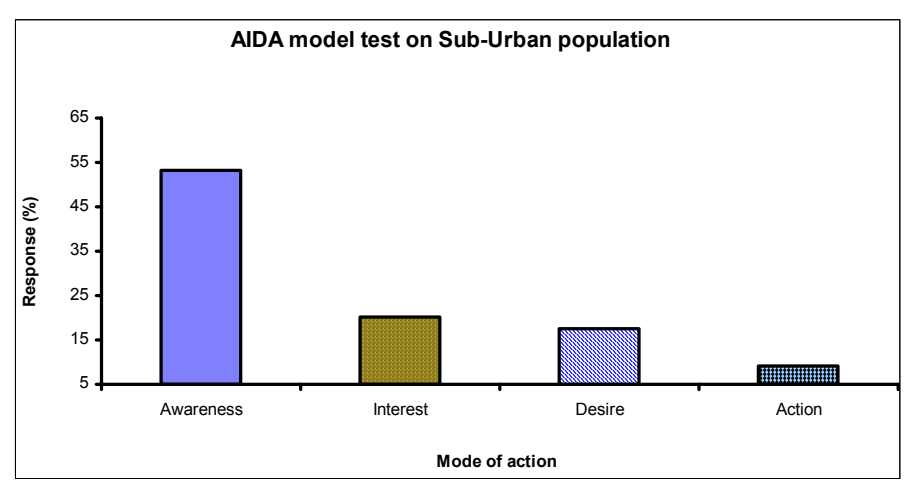

Fig.5: AIDA Model Test on Sub-urban Population 
of action in sub-urban society became higher than that of urban society but they were not significantly differed. This difference could be due to frequent unavailability of the product in sub-urban areas. The comparative differences are shown in Fig. 5, Fig. 6 and Fig. 7.

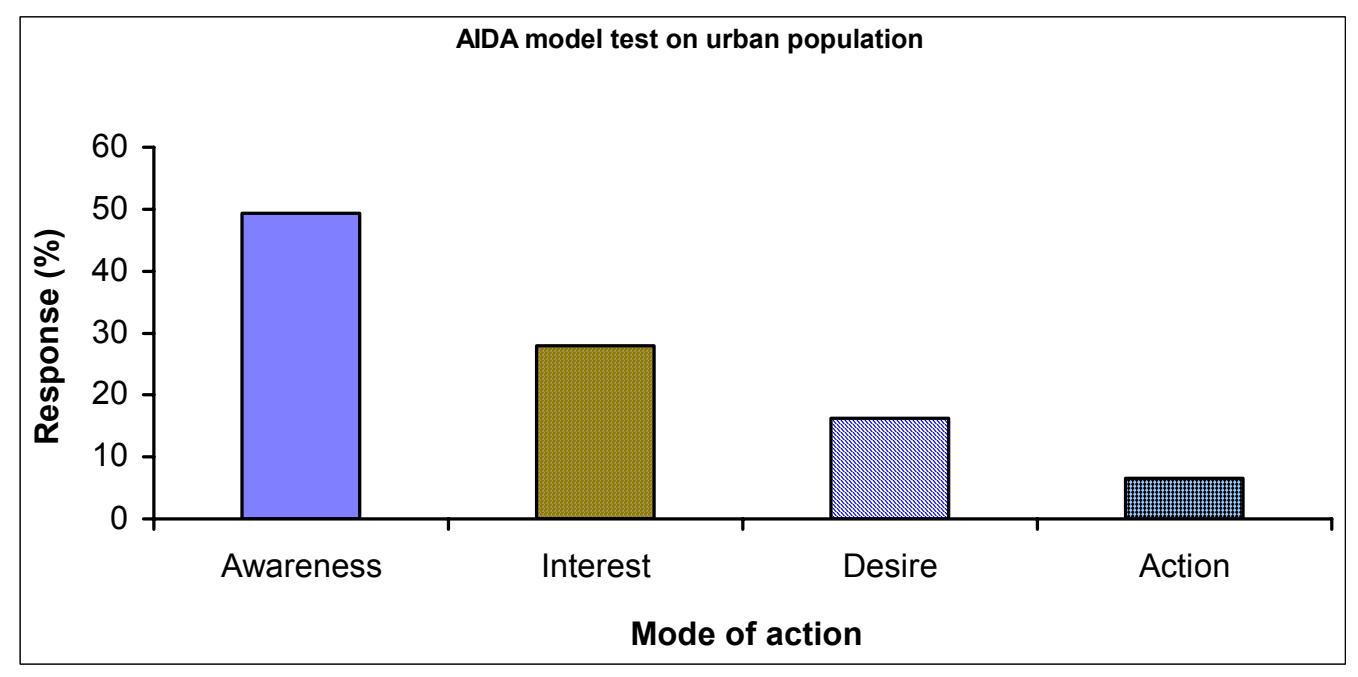

Fig.6: AIDA Model Test on Urban Population

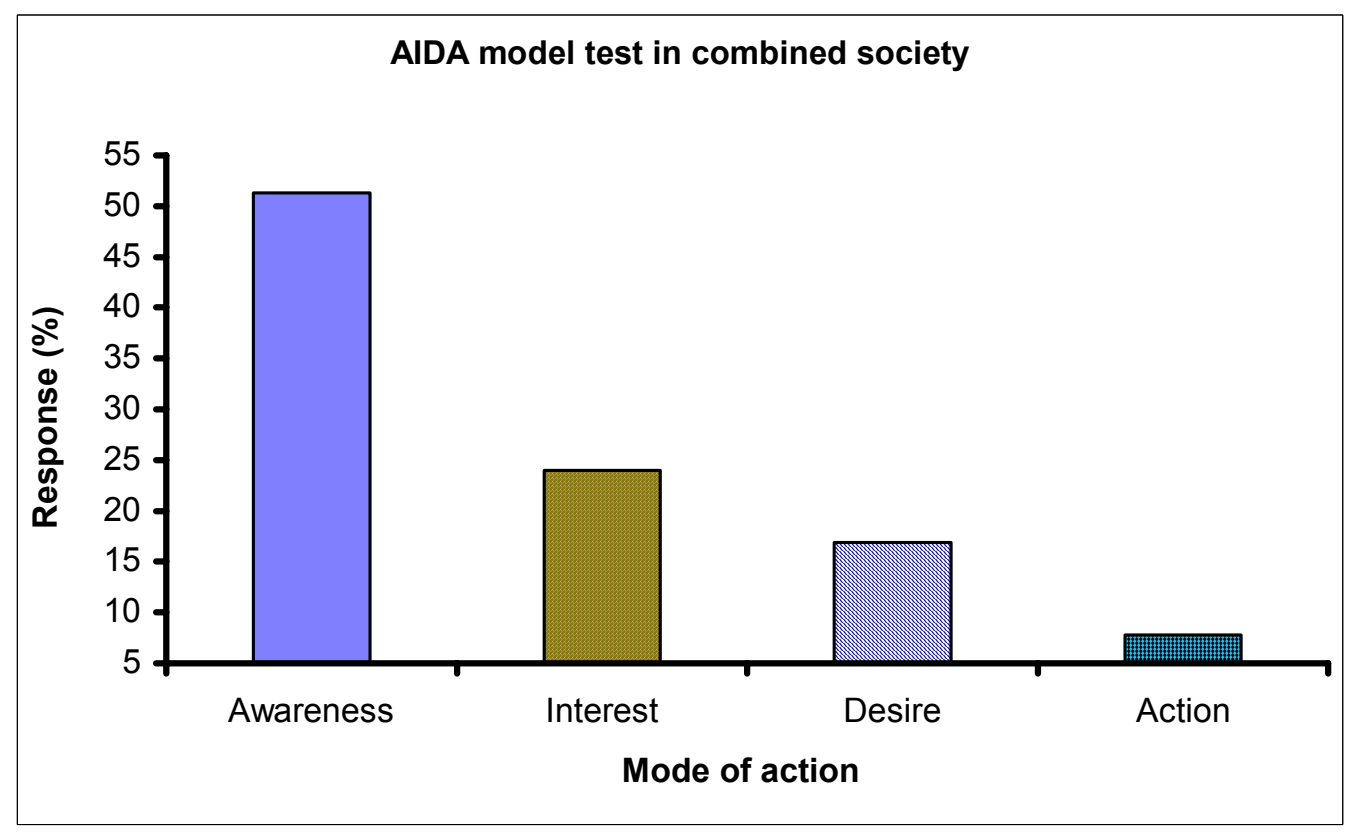

Fig. 7: AIDA Model Test on Combined Society.

Fig. 5 and Fig. 6 represent the respondents' view towards TV advertisement in both urban and suburban sector in Nepal. Respondents of both urban and sub-urban areas have given their views as deemed by Lewis. Fig. 7 represents AIDA model test on combined society. Fifty percent respondents' focus on awareness, $25 \%$ said interest and $15 \%$ and $10 \%$ said desire and action respectively. The conclusion here is that the awareness, interest, desire and action are in descending order and form an inverted pyramid 


\section{Conclusions}

Today, the word advertising is a very common term for everybody. We see in Television, in the sky, on the matchbox, in newspapers, on the trash containers, on our mail, transport, on billboards; we hear it on radio, FM and so on. It has become part of our daily life and everyone is conscious of it. About $67 \%$ of average audience watches domestic channels such as Nepal TV, Channel Nepal, Kantipur TV, Image Channel. So the advertisers should select domestic channel for the advertisement of their products.

The recall percentage is higher in urban area. The implicit reason of this is that urban audiences have more chance to watch television as compare to the rural audiences. In case of Nepal, due to limited production, the producers less conscious of ad than that in other countries. In TV Commercials, view, illustrations and slogans are major three factors that can help to recall advertisement. Unequivocally, the advertisers should focus on these factors while preparing ad on TV.

Present ads are unable to touch heart of the viewers. Advertisers prepare TVC without proper research. The present TVC are more provocative, lacking appropriate information, and does not communicate sufficiently to audiences due to language barrier. So, the producer should focus on these areas to improve the quality of ad.

As stated by Lewis in 1998, the hierarchy of AIDA model has been verified both in sub-urban and urban society of Nepal. The awareness, interest, desire and action are in descending order. Relative proportion of action in sub-urban society became higher than that of urban society but they were not significantly different. This marginal difference could be due to frequent unavailability of the product in sub-urban areas.

\section{REFERENCES}

Supriya, Biswas. 1999. Behavioral Impact of Advertisements. np.

Schiffman, Leon G. and Kanuk Leslie Lazar.1996. Consumer Behavior, 6th ed. np. Sontakki, C. N. 1996. Advertising, 2nd ed. New Delhi: Kalyani Publishers. 